\title{
Early expression and high prevalence of islet autoantibodies for DR3/4 heterozygous and DR4/4 homozygous offspring of parents with Type I diabetes: The German BABYDIAB study
}

\author{
M. Schenker ${ }^{1}$, M. Hummel ${ }^{1}$, K. Ferber ${ }^{1}$, M. Walter ${ }^{1}$, E. Keller ${ }^{2}$, E.D. Albert ${ }^{2}$, H.-U. Janka ${ }^{3}$, C. Kastendiek ${ }^{3}$, \\ M. Sorger ${ }^{4}$, F. Louwen ${ }^{5}$, A.-G. Ziegler ${ }^{1}$ \\ ${ }^{1}$ Third Medical Department, Munich-Schwabing Hospital and Diabetes Research Institute, Munich, Germany \\ ${ }^{2}$ Laboratory for Immunogenetics, Ludwig-Maximilians-University, Munich, Germany \\ ${ }^{3}$ Central Hospital Bremen-North, Bremen, Germany \\ ${ }^{4}$ Medical Polyclinic, Bonn, Germany \\ ${ }^{5}$ Obstetric Department, University of Münster, Germany
}

\section{Abstract}

Aims/hypothesis. Islet autoantibodies precede the clinical onset of Type I (insulin-dependent) diabetes mellitus. The cumulative development of such autoantibodies in infants followed from birth and in particular infants with high-risk HLA genotypes is poorly defined, but such information is essential to design trials to prevent islet autoimmunity.

Methods. HLA genotypes were determined in offspring of parents with Type I diabetes who were followed from birth for at least 2 years (median followup: 3.1 years) and who were characterised for the expression of insulin, GAD65, IA-2 and islet cell autoantibodies at birth, 9 months, 2 and 5 years of age. Results. The HLA genotypes DRB1*03/04(DQB1 *57non-Asp) and DRB1*04/04(DQB1*57non-Asp) were present in $7.1 \%$ and $5.0 \%$ of offspring of parents with Type I diabetes. The frequency of both genotypes was increased in offspring who developed islet autoantibodies within the first 2 years of life $(27.3 \%$ vs $5.5 \%$, odds ratio $6.3[p=0.002]$ and $22.7 \%$ vs $4.2 \%$, odds ratio $6.6[p=0.003])$ and half of all offspring who developed antibodies had these genotypes. Other genotypes were not associated with an increase in risk. By life-table analysis, the cumulative risk of developing islet autoantibodies by the age of 2 years was $20 \%$ (95\% CI 9.4,30.6) for offspring carrying either the $D R B 1 * 03 / 04(\mathrm{DQB} 1 * 57$ non-Asp) or the DRB1*04/ 04(DQB1*57non-Asp) genotype compared with $2.7 \%(95 \%$ CI 1.2,4.2) for offspring without these genotypes $(p<0.0001)$.

Conclusion/interpretation. These data show that early appearance of islet autoantibodies is remarkably frequent for $D R 3 / 4$ heterozygous and $D R 4 / 4$ homozygous offspring and indicate that primary prevention could be considered once available in an offspring cohort selected for these genotypes. [Diabetologia (1999) 42: 671-677]

Keywords HLA genotype, Type I diabetes, islet autoimmunity, autoantibody appearance.
Type I (insulin-dependent) diabetes mellitus is preceded by a long period without any symptoms during which autoimmune responses are activated and islet

Received: 16 December 1998 and in final revised form: 25 January 1999

Corresponding author: Dr. A.-G. Ziegler, Krankenhaus München-Schwabing, Diabetes Research Institute, Kölner Platz 1, D-80804 Munich, Germany

Abbreviations: IAA Insulin autoantibodies, GADA glutamic acid decarboxylase autoantibodies, IA2A antibodies to the protein tyrosine phosphatase IA-2, ICA islet cell autoantibodies. autoantibodies can be detected in the circulation [1-4]. Two collaborative studies in Europe and America are currently testing intervention therapies using nicotinamide (ENDIT) or insulin (DPT-1) to prevent or delay the onset of Type I diabetes. Both studies treat relatives of patients with Type I diabetes when autoantibodies are consistently raised and in the case of parenteral insulin [5] beta-cell function is already impaired. More recently, new encouraging strategies of peptide vaccination have been proposed aimed at intervening early in life to prevent the initiation of islet autoimmunity $[6,7]$. Such trials of primary intervention could eventually be designed when populations at risk for the development of islet autoimmunity can 
be genetically defined and risk estimates of the frequency of islet autoantibodies in infancy are available.

We have shown previously that persistent autoantibodies often appear by the age of 2 years in offspring of parents with Type I diabetes $[8,9]$. Recent genome-wide mapping has confirmed that HLA class II genes confer the greatest genetic risk for Type I diabetes [10-12]. In Caucasians Type I diabetes is strongly associated with HLA DR3 and DR4 alleles, and diabetes risk is particularly high for people with DR3/4 and DR4/4 genotypes which contain DQB1 alleles carrying non-Asp at residue 57 [13]. Taking advantage of the German BABYDIAB study where we prospectively followed such offspring from birth, we here analysed the frequency of HLA genotypes and their associated risk for early expression of islet autoantibodies in infancy in order to design primary prevention trials in susceptible people.

\section{Subjects and methods}

Subjects. Since 1989 we have conducted a prospective German multicentre study of infants followed from birth. The "BABYDIAB" study of children from mothers or fathers with Type I diabetes investigates the temporal development of the responses of insulin autoantibodies (IAA), glutamic acid decarboxylase autoantibodies (GADA), the antibodies to the protein tyrosine phosphatase IA-2 (IA2A), and islet cell autoantibodies (ICA) at birth (cord blood) and at 9 months, 2, 5 and 8 years of age in all children $[8,9]$. At 2 years of age, EDTA blood is requested from parents and the index child for HLA typing. Of 1429 children recruited at birth, 674 have reached the age of 2 years. Of these, 628 have participated in the 2year follow-up visit (442 offspring had a mother with Type I diabetes, 171 offspring were offspring of a father with Type I diabetes, and for 15 offspring both parents were diabetic; median follow-up time from birth $=$ median age: 3.3 years, range $1.5-8.7$ years). There were 46 families $(6.8 \%)$ who refused to participate at the 2-year visit or were lost to follow-up because they had moved to an unknown address. We obtained EDTA blood samples for HLA typing from 477 (76\%) of 628 offspring (334 of a mother, 130 of a father and 13 of both parents with Type I diabetes, median follow-up time from birth = median age: 3.1 years, range $1.3-8.5$ years). The major reason for not obtaining EDTA samples from 151 offspring was that the families did not always bring collection tubes which had been sent to each of them from our centre and EDTA tubes were not routinely available in the surgery of each family's general practioner. For those with islet autoantibodies samples for HLA typing could be obtained in subsequent visits. For ethical reasons, we could not ask families with antibody negative children for extra visits between 2 and 5 years of age to complete HLA typing but for offspring who reached 5 years of age missing EDTA samples were obtained at the 5-year follow-up visit. There were no differences in baseline characteristics (age, sex, relation to proband, diabetes duration and age of the parent) and clinical features (weight, height) between offspring who were HLA typed and those where no EDTA blood was available for HLA typing ( $z$ test).

HLA typing. We determined HLA class II alleles, HLADRB1, HLA-DQA1 and HLA-DQB1, using PCR-amplified DNA and non-radioactive oligonucleotide probes (sequence- specific oligonucleotide typing SSO). The HLA laboratory was not aware of antibody results prior to typing. Genomic DNA was isolated from fresh peripheral blood cells (EDTAblood) by the salting-out procedure described in the 11th workshop report [14]. After isolation, the DNA was resuspended in TE-buffer (1 mmol/l TRIS-HCl; $0.1 \mathrm{mmol} / \mathrm{l}$ EDTA, $\mathrm{pH} 8.0$ ), adjusted to a final concentration of $250 \mu \mathrm{g} /$ $\mathrm{ml}$ and stored at $-20^{\circ} \mathrm{C}$ until used. Genomic DNA $(1 \mu \mathrm{g})$ was amplified by PCR in a $100 \mu \mathrm{l}$ reaction volume using 25 pmol of primers [14], $20 \mathrm{nmol}$ dNTP's, 2.5 units Taq Polymerase and buffer $(10 \mathrm{mmol} / \mathrm{l}$ TRIS-HCl pH 8.3, $50 \mathrm{mmol} / \mathrm{l}$ $\mathrm{KCl}, 1.5 \mathrm{mmol} / 1 \mathrm{MgCl}_{2}, 0.001 \%$ gelatin). After a denaturation step at $94^{\circ} \mathrm{C}$ for $10 \mathrm{~min}$, the samples were subjected to 33 cycles of PCR amplification in a Perkin Elmer Cetus 9600 thermocycler (Perkin Elmer Roché Molecular Systems, NJ, USA) (DRB1generic: $94^{\circ} \mathrm{C} 1 \mathrm{~min}, 53^{\circ} \mathrm{C} 1 \mathrm{~min}, 72^{\circ} \mathrm{C}$ $1 \mathrm{~min}$; DQA1: $94^{\circ} \mathrm{C} 1 \mathrm{~min}, 52^{\circ} \mathrm{C} 1 \mathrm{~min}, 72^{\circ} \mathrm{C} 1 \mathrm{~min}$; DQB1: $\left.94^{\circ} \mathrm{C} 45 \mathrm{~s}, 53^{\circ} \mathrm{C} 45 \mathrm{~s}, 72^{\circ} \mathrm{C} 45 \mathrm{~s}\right)$. Amplified DNA products were verified by agarose gel electrophoresis $(1.2 \%)$. For the dot blot hybridization the amplified DNA $(2 \mu \mathrm{l})$ was spotted onto nylon membranes (Boehringer Mannheim, Mannheim, Germany) and hybridized with 15 DRB generic, 17 DQA and 20 DQB specific oligonucleotides, respectively [14]. The hybridized oligonucleotides $3^{\prime}$ end labelled with digoxigenin-11-2',3'-dideoxyuridine-5' -triphosphate (Dig-11-ddUTP, Boehringer Mannheim) were detected using anti-dioxigeninAP Fab fragments (Boehringer Mannheim) and made visible with the chemiluminescent substrate CSPD (Boehringer Mannheim) [15, 16]. The HLA-DRB1, HLA-DQA1 and HLA-DQB1 alleles were named according to the nomenclature of 1996 [17]. The alleles $D Q A 1 * 03011$ and *0302 were indistinguishable by SSO and were therefore referred to as $D Q A 1 * 03$. Also the alleles $D Q B 1 * 0201$ and $* 0202$ were indistinguishable and were referred to as $D Q B 1 * 02$.

Classification of HLA genotypes. For analysis, offspring were grouped according to diabetes associated and non-associated HLA genotypes. Offspring with $D R 3$ or $D R 4$ were grouped as $D R 3 / 3, D R 3 / 4, D R 3 / X$ and $D R 4 / X$ where $\mathrm{X}$ is a non- $D R 3$ and non- $D R 4$ containing haplotype. In relevant cases, parents of offspring were also typed to confirm that their offspring were homozygotes for $D R 3 / 3$ or $D R 4 / 4$. Offspring who were $D R B 1 * 03 / 04$ heterozygous with DQB1 alleles containing a non-Asp at residue $57(* 0302, * 0304, * 0305$, or $* 0307)$ were sub-grouped to $D R 3 / 4(\mathrm{DQB} 1 * 57$ non-Asp); $D R 3 / 4$ heterozygous offspring with a $D Q B 1 * 0301, * 0303$, or $* 0306$ allele were grouped to $D R 3 / 4(\mathrm{DQB} 1 * 57 \mathrm{Asp})$. Similarly, $D R B 1 * 04 / 04$ homozygous offspring with both DQB1 alleles containing a nonAsp at residue $57(* 0302, * 0304, * 0305$, or $* 0307)$ were grouped to $D R 4 / 4(\mathrm{DQB} 1 * 57$ non-Asp). We grouped $D R 4 / 4$ offspring with one or two $D Q B 1$ allele containing Asp at residue 57 to $D R 4 / 4(\mathrm{DQB} 1 * 57 \mathrm{Asp})$. Children with $D R 2$ and at least one $D Q B 1 * 0602$ allele were grouped into " $D R B 1 * 02 /$ $Y(D Q B 1 * 0602)$ ", including 19 children who had $D R 2 /$ $4(D Q B 1 * 0602 / * 57$ non-Asp $)$ and 24 who had $D R 2 /$ $3(D Q B 1 * 0602 / * 0201)$.

Autoantibody determination. Autoantibodies to insulin (IAA), glutamic acid decarboxylase (GADA), the protein tyrosine phosphatase IA-2 (IA2A) and islet cells (ICA) were analysed as described previously [9]. The upper limit of normal was defined by the 99th centile of antibody levels in non-diabetic control children (IAA $50 \mathrm{nU} / \mathrm{ml}$, GADA 13 units, IA2A 5 units, ICA 5 JDF-units; [9]). Antibody assays were entered into the Antibody Proficiency Programme. The IAA assay achieved a specificity of $100 \%$ and a sensitivity of $100 \%$ (4th workshop), 
Table 1. Frequency of HLA genotypes in BABYDIAB offspring

\begin{tabular}{|c|c|c|c|c|c|c|c|}
\hline \multirow[t]{2}{*}{ HLA genotype } & \multicolumn{2}{|c|}{ total cohort } & \multicolumn{2}{|c|}{$\begin{array}{l}\text { offspring from mothers } \\
\text { with Type I diabetes }\end{array}$} & \multicolumn{2}{|c|}{$\begin{array}{l}\text { offspring from fathers } \\
\text { with Type I diabetes }\end{array}$} & \multirow{2}{*}{$\begin{array}{l}\text { both parents } \\
\text { with Type I } \\
\text { diabetes } \\
n\end{array}$} \\
\hline & $n$ & $\%$ & $n$ & $\%$ & $n$ & $\%$ & \\
\hline DR 3/4 (DQB1*57non-Asp) & 34 & 7.1 & 21 & 6.3 & 11 & 8.5 & 2 \\
\hline DR 3/4 (DQB1*57Asp) & 11 & 2.3 & 9 & 2.7 & 2 & 1.5 & \\
\hline DR 3/X & 82 & 17.2 & 62 & 18.6 & 15 & 11.5 & 5 \\
\hline DR 4/X & 153 & 32.0 & 104 & 31.1 & 46 & 35.4 & 3 \\
\hline DR 2/Y (DQB1*0602) & 67 & 14.0 & 42 & 12.6 & 25 & 19.2 & \\
\hline $\mathrm{DR} X / \mathrm{X}$ & 78 & 16.4 & 58 & 17.4 & 20 & 15.4 & \\
\hline total typed & 477 & & 334 & & 130 & & 13 \\
\hline
\end{tabular}

the GADA assay $100 \%$ and $94 \%$ (3rd workshop), the IA2A assay $100 \%$ and $100 \%$ (1st workshop) and the ICA assay $100 \%$ and $67 \%$ (9th workshop), respectively.

Classification of autoantibody status of offspring. In all 628 offspring sera were obtained for the determination of islet autoantibodies at birth, 9 months and 2 years of age. We classified 23 offspring as 'autoantibody positive', defined as having at least one raised autoantibody specificity in at least two follow-up samples including the most recent serum sample. Typing for HLA was carried out in 22 of these. Of the 23 offspring with persistent autoantibodies 10 have progressed to diabetes. There were 592 offspring who had no raised autoantibodies in both their 9 month and 2 years sample and were classified as 'autoantibody negative'. A further five had raised autoantibodies in one sample, but were negative in the most recent blood sample and were also included in the antibody negative group. In 448 of those 597 offspring HLA typing was available. In a further 8 offspring one or more autoantibodies were detected but no follow-up sample for confirmation of results was available at that time. These cases were neither included into the group of antibody 'positive' nor antibody 'negative' offspring and thus excluded from the analysis of the frequency of HLA genotypes and the life table calculation. None of these offspring has developed Type I diabetes to date and seven were HLA-typed and three carried the DR3/4(DQB1*57non-Asp) genotype.

Statistical analysis. Fisher's exact test was used to analyse differences between offspring from mothers and fathers with Type I diabetes and between offspring with and without islet autoantibodies. Kaplan-Meier life-table analysis was used to determine the cumulative development of the first antibody event. Follow-up started at birth and ended when antibodies were first detected or the day of the most recent blood sample. In children from mothers with diabetes, antibodies detected before age 0.5 years were excluded because of potential interference from antibodies acquired transplacentally, and in children from fathers with diabetes, IAA detected at birth were excluded because of potential artefact in IAA measurement in cord blood [9]. Antibody events were experienced at birth and at intervals between 0.5 and 1.5 years (9-month visit), 1.5 and 2.5 years (2-year visit) and 4.5 and 5.5 years (5-year visit). For all statistical methods the Statistical Package for Social Sciences (SPSS, Chicago, Ill., USA) was used.

\section{Results}

HLA genotype frequency in offspring of parents with Type I diabetes. Of 477 HLA typed offspring 34 $(7.1 \%)$ had the genotype $D R B 1 * 03 / 04(\mathrm{DQB} 1$ *57non-Asp) and $24(5.0 \%)$ had $D R B 1 * 04 /$ 04(DQB1*57non-Asp) (Table 1). No significant difference in the frequency of HLA genotypes was seen between offspring from affected mothers or fathers.

HLA genotype and antibody development. By the age of 2 years $23(3.7 \%)$ offspring developed islet autoantibodies (Table 2). Of these 15 were offspring from a mother with Type I diabetes, 6 from a father with Type I diabetes and for 2 children both parents were diabetic. The median age when the first antibody appeared was 1.5 years (range 0.6-2.4 years). Two offspring had IAA only, 4 offspring had 2 antibodies, 3 had 3 antibodies, and 14 had all four antibody specificities. Of the 22 who were HLA typed, 8 (36\%) had genotypes with $D R 3$ and 17 (77\%) genotypes with $D R 4(\mathrm{DQB} 1 * 57$ non-Asp); 6 had the $D R 3 /$ 4 (DQB1*57non-Asp) and 5 the DR4/4(DQB1 *57non-Asp) genotype.

Table 3 compares the frequency of HLA DRB1/ DQB1 genotypes in offspring with and without islet autoantibodies. We found HLA $D R B 1 * 03$ haplotypes in a similar frequency in offspring with $(18 \%)$ and without $(15 \%)$ islet antibodies. The frequency of HLA $D R B 1 * 04(\mathrm{DQB} 1 * 57$ non-Asp) haplotype was higher in offspring with islet antibodies $(50 \%$ vs $25 \%$ in offspring without antibodies $p<0.01)$. Only genotypes with HLA $D R B 1 * 04(\mathrm{DQB} 1 * 57$ non-Asp) were more prevalent in offspring with islet antibodies. The frequency of the DRB1*03/04(DQB1 *57nonAsp) genotype was $27.3 \%$ in offspring who had islet autoantibodies by 2 years of age compared with $5.5 \%$ in offspring without these autoantibodies (odds ratio 6.3 [95\% CI 2.3, 17.5], $p=0.002)$. The frequency of $D R B 1 * 04 / 04(\mathrm{DQB} 1 * 57$ non-Asp) was $22.7 \%$ in offspring with islet autoantibodies and $4.2 \%$ in offspring without antibodies (odds ratio 6.6, $p=0.003$ ). 
Table 2. BABYDIAB children with detectable islet autoantibodies

\begin{tabular}{|c|c|c|c|c|c|c|c|c|}
\hline $\begin{array}{l}\text { family } \\
\text { number }\end{array}$ & proband & HLA DRB1 & HLA DQA1 & HLA DQB1 & $\begin{array}{l}\text { age at first } \\
\text { antibody } \\
\text { (years) }\end{array}$ & total antibodies & $\begin{array}{l}\text { age at } \\
\text { last sample } \\
\text { (years) }\end{array}$ & $\begin{array}{l}\text { age at } \\
\text { diabetes } \\
\text { onset (years) }\end{array}$ \\
\hline $2223\left(5^{\mathrm{a}}\right)$ & mother & 03,04 & 0,503 & 02,0302 & 2.1 & IAA, GADA, IA2A, ICA & 4.6 & \\
\hline $1649(4)$ & mother & 03,0401 & 0501,03 & 02,0302 & 0.9 & IAA, GADA, IA2A, ICA & 6.0 & \\
\hline 1724 & father & 03,0401 & 0501,03 & 02,0302 & 1.1 & IAA, GADA, IA2A, ICA & 5.6 & \\
\hline $2277(10)$ & father & 03,0401 & 0501,03 & 02,0302 & 1.7 & IAA, GADA, IA2A, ICA & & 1.8 \\
\hline 3941 & mother & 04,04 & 03,03 & 0302,0302 & 2.0 & IAA, GADA, IA2A, ICA & & 3.8 \\
\hline 4412 & mother & 0402,0405 & 03,03 & 0302,0302 & 1.7 & IAA & 3.4 & \\
\hline 4215 & both & 04,04 & 03,03 & 0304,0302 & 2.1 & IAA, GADA, IA2A & 3.8 & \\
\hline 4050 & mother & 0404,0408 & 03,03 & 0302,0304 & 0.9 & IAA, GADA, IA2A, ICA & 3.2 & \\
\hline 2905 & mother & 04,08 & 03,0401 & 0302,0402 & 2.4 & IAA, GADA, IA2A & 3.6 & \\
\hline 3929 & father & 04,11 & 03,0501 & 0302,0301 & 2.1 & IAA, GADA, IA2A, ICA & 4.2 & \\
\hline 1068 & mother & 03,01 & 0501,0101 & 0201,0501 & 0.9 & IAA, GADA & 5.4 & \\
\hline $1872(3)$ & mother & 01,01 & 0101,0101 & 0501,0501 & 2.0 & IAA, ICA & & 4.9 \\
\hline 1628 & father & 11,12 & 0501,0102 & 0301,0502 & 2.0 & IAA, GADA, IA2A, ICA & & 3.2 \\
\hline $1032(2)$ & mother & 11,02 & 0501,0102 & 0301,0502 & 0.8 & IAA, GADA, IA $2 A$, ICA & & 7.1 \\
\hline $4161(11)$ & father & missing & missing & missing & 0.9 & IAA, ICA & & 2.4 \\
\hline
\end{tabular}

${ }^{a}$ number in paranthesis corresponds to case number given in Table I of reference 9

Table 3. Frequency of HLA genotypes in BABYDIAB offspring with and without detectable islet autoantibodies

\begin{tabular}{|c|c|c|c|c|}
\hline HLA genotype & $\begin{array}{l}\text { antibody negative } \\
\text { by } 2 \text { years of age } \\
n(\%)\end{array}$ & $\begin{array}{l}\text { antibody positive } \\
\text { by } 2 \text { years of age } \\
n(\%)\end{array}$ & $\begin{array}{l}\text { odds ratio to develop autoantibodies } \\
\text { by } 2 \text { years of age }\end{array}$ & $p$ value \\
\hline DR 3/3 & $16(3.6)$ & 0 & 0.6 (95\% CI 0.04-10.3) & 0.5 \\
\hline DR 3/4 (DQB1*57Asp) & $11(2.4 \%)$ & 0 & 0.8 (95\% CI 0.05-14.0) & 0.6 \\
\hline DR 3/X & $80(17.9 \%)$ & $2(9.1 \%)$ & 0.5 (95\% CI 0.1-2.2) & 0.4 \\
\hline DR 4/4 (DQB1*57non-Asp) & $19(4.2 \%)$ & $5(22.7 \%)$ & $6.6(95 \%$ CI $2.2-19.8)$ & 0.003 \\
\hline $\mathrm{DR} 2 / \mathrm{Y}(\mathrm{DQB} 1 * 0602)^{\mathrm{c}}$ & $67(15.0 \%)$ & 0 & 0.1 (95\% CI $0.006-1.7)$ & 0.03 \\
\hline $\mathrm{DR} X / \mathrm{X}$ & $75(16.7 \%)$ & $3(13.6)$ & 0.8 (95\% CI $0.2-2.8)$ & 0.8 \\
\hline total typed & 448 & 22 & & \\
\hline
\end{tabular}

a all had also one DQB1*57non-Asp allele,

${ }^{\mathrm{b}}$ including 134 antibody negative and all 6 antibody positive with one DR 4 (DQB1*57non-Asp) haplotype,

${ }^{c}$ including 19 with one DR 4 (DQB1*57non-Asp) haplotype

Together, $11(50 \%)$ offspring with islet autoantibodies had either the $D R 3 / 4(\mathrm{DQB} 1 * 57 \mathrm{non}-\mathrm{Asp})$ or DR4/4(DQB1*57non-Asp) genotype compared with $44(9.8 \%)$ offspring without islet antibodies (odds ratio 9.2 [95\% CI 3.8-22.4], $p<0.0001)$. No other genotypes, including $D R 3 / 3, D R 3 / 4$ (DQB1*57Asp), DR3/ $X$, and $D R 4 / X$ were associated with an increased antibody frequency. Genotypes containing $D R 2(D Q B 1$ $* 0602)$ were absent in offspring with islet autoantibodies ( $0 \%$ vs $15 \%, p=0.03)$.

There were ten offspring with islet autoantibodies who developed Type I diabetes. All had multiple islet autoantibodies and two had the DR3/4(DQB1
*57non-Asp) and two the DR4/4(DQB1*57nonAsp) genotype. Autoantibody levels of IAA, GADA, and IA2A from birth until diabetes onset of these four offspring (numbers 4005, 2277, 1088, 3941) are shown in Fig. 1.

Cumulative risk for autoantibody development with respect to HLA genotype. By life-table analysis, the cumulative risk of developing a first islet autoantibody event by 2 years of age was $20.0 \%$ (95\% CI 9.4, 30.6) for offspring with either $D R 3 / 4(\mathrm{DQB} 1 * 57$ non-Asp) heterozygous or DR4/4(DQB1*57non-Asp) homozygous genotypes compared with $2.7 \%$ (95\% CI 1.2 , 

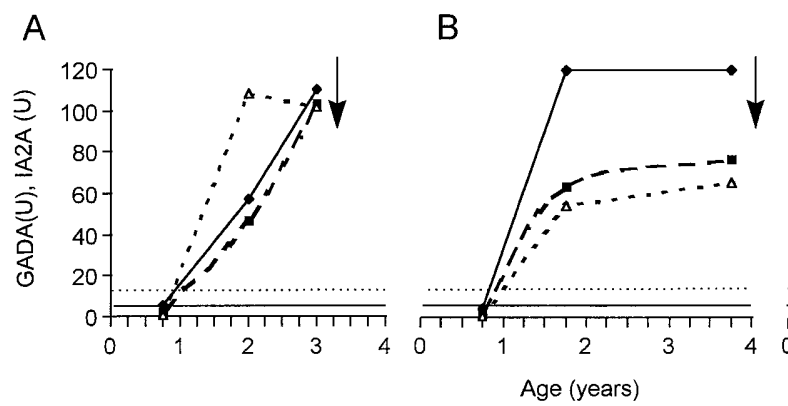

C

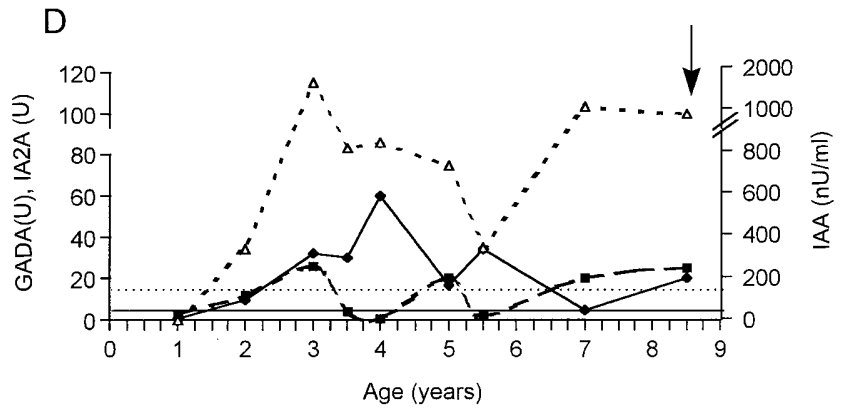

Fig.1.A-D Autoantibody levels of IAA (-), GADA (-- - , and IA2A $(\cdots)$ from birth in the four offspring with DR3/4 or DR4/4 genotypes who developed Type I diabetes (A no 4005, B no 3941, C no 2277, D no 1088, see also Table 2). Diabetes onset date is marked with an arrow. Horizontal lines indicate the upper limit of normal for IAA and IA2A (-) and for GADA $(\cdots)$

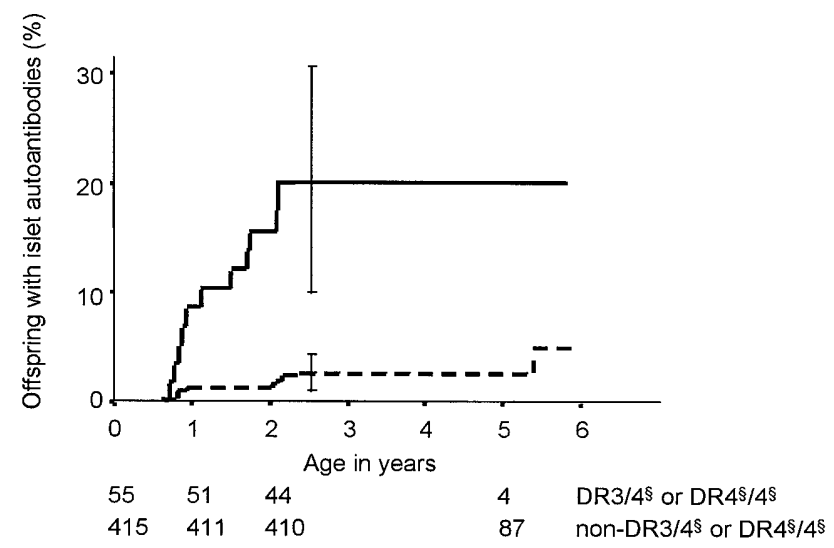

Fig. 2. Kaplan-Meier life-table analysis: cumulative risk of islet autoantibody development in offspring from parents with Type I diabetes depending on the presence $(-)$ or absence $(---)$ of a $D R 3 / 4(\mathrm{DQB} 1 * 57$ non-Asp) or $D R 4 / 4$ (DQB1*57non-Asp) genotype $(p<0.0001) .95 \%$ confidence intervals are given. $\S$ indicates a non-Asp containing DQB1 allele

4.2) for offspring without these genotypes $(p<0.0001$, Fig. 2).

\section{Discussion}

In this study we analysed the association of HLA class II genotypes and the development of islet auto- antibodies in early life in offspring of parents with Type I diabetes. Offspring carrying the high risk $D R 3 / 4$ (DQB1*57non-Asp) or DR4/4(DQB1*57nonAsp) genotypes had a sevenfold risk of developing islet autoantibodies by age 2 years. Of all offspring, $12.1 \%$ had these genotypes and their cumulative risk of expressing raised autoantibody by the age of two years was $20 \%$ compared with $2.7 \%$ in offspring without these genotypes. Other genotypes were not associated with an increase in risk. Of 22 offspring with islet autoantibodies, $11(50 \%)$ had either the $D R 3 / 4$ or $D R 4 / 4$ genotype and 4 have already progressed to diabetes.

The $D R 3 / 4$ genotype has been shown previously to be associated with a more rapid progression to diabetes in islet autoantibody positive siblings of patients with Type I diabetes [18]. Moreover, in the DAISY study, $62.5 \%$ of $D R 3 / 4$ positive children with islet autoantibodies were diabetic before the age of 5 years [19]. Our data now indicate that not only the rate of progression could be accelerated in DR3/4 positive people with beta-cell autoimmunity but also the risk of developing this autoimmunity is remarkably enhanced in early life. Ascertainment with respect to HLA typing in this study was $76 \%$ with a minor bias towards the antibody positive offspring and, therefore, the calculated $20 \%$ islet autoantibody risk in offspring with high-risk HLA genotypes is possibly higher than the true risk. Based upon the $9.7 \%$ prevalence of these genotypes in the HLA-typed autoantibody negative offspring, the true risk is estimated to be $16 \%$ which is still considerably higher than autoantibody risk in offspring without the high-risk HLA genotypes. The risk of the development of islet autoimmunity in offspring appears to be more strongly associated with the presence of $D R 4$ and diabetes susceptible DQA1/DQB1 non-Asp alleles since first- 
ly, risk was not increased for offspring with $D R 3$ in the absence of $D R 4$, secondly, risk was increased for offspring with DR4/4(DQB1*57non-Asp) and thirdly, no offspring with $D R 3 / 4(\mathrm{DQB} 1 * 57 \mathrm{Asp})$ or $D R 4 /$ 4(DQB1*57Asp) have developed antibodies. These observations also support the notion that DR4(DQB1*57non-Asp) is the HLA haplotype most strongly associated with Type I diabetes in childhood.

The observation that $20 \%$ of $D R 3 /$ $4(\mathrm{DQB} 1 * 57 \mathrm{non}-\mathrm{Asp})$ and $D R 4 / 4(\mathrm{DQB} 1 * 57$ nonAsp) offspring of parents with Type I diabetes develop autoantibodies by two years of age may facilitate the design of intervention trials. The use of persistent antibody appearance rather than diabetes onset as the major outcome variable to determine efficacy of prevention strategies would considerably reduce trial length. This seems a feasible strategy for primary intervention trials since we have shown that the definition of antibody positivity used in this study is highly associated with subsequent progression to disease. It is likely that any primary intervention protocol for Type I diabetes should be started shortly after birth since islet autoantibodies can already be detected at 9 months of age. A major disadvantage of primary prevention trials is that without efficient genetic selection, the large majority of subjects enrolled will never develop disease and, as a consequence, the sample size required is enormous. Selection for risk on a genetic basis will both reduce trial size and concentrate on subjects with an increased risk of developing disease.

Based on the results of this study, it is possible to design a trial for the prevention of the appearance of diabetes-associated islet autoantibodies. In a cohort with a $20 \%$ risk of developing islet antibodies, a trial aimed at detecting a $50 \%$ reduction in antibody development with a power of $80 \%$, an alpha $(p)$ of 0.05 and a $10 \%$ drop-out rate would require 220 subjects in each arm. Selection of offspring with the $D R 3 /$ 4(DQB1*57non-Asp) genotype would include $7.1 \%$ of all offspring of parents with Type I diabetes, including $27 \%$ of those who develop persistent islet autoantibodies by 2 years of age. If a treatment and a placebo arm were used and a refusal to participate of $20 \%$ assumed, a total of 7437 offspring of parents with Type I diabetes would need to be typed for HLA DR3 and 04 and subsequently DQB1*57nonAsp alleles. If offspring with $D R 4 / 4(\mathrm{DQB} 1 * 57$ nonAsp) genotypes were also included, the number of offspring requiring HLA typing would be reduced to 4364 and half of those who develop persistent islet autoantibodies by 2 years of age would participate. The HLA typing for DR4/4(DQB1*57non-Asp) is, however, less straightforward since generic typing for non-DR4 alleles must be carried out to exclude the $D R 4 / X$ genotypes and parents may also require typing for $D R 4$ to confirm they are $D R 4 / 4$ homozy- gotes in relevant cases. A disadvantage of selection on a genetic basis is that potentially $50 \%$ of children developing islet autoantibodies and diabetes do not express these high-risk genotypes (Table 2) and it cannot be assumed that any given therapy will be effective for all genotypes. It is our experience from the BABYDIAB study that as cord blood samples can be used for HLA typing and are relatively easy to collect typing at this time is preferable and avoids taking blood from the child which is painful or the use of mouth swabs. It should also be considered that recruitment of over 4000 offspring of parents with Type I diabetes is a major undertaking requiring multicentric or multi-national participation. Intervention therapies should, therefore, have a strong rationale and adequate validation prior to use in such trials. 'Vaccination' trials with insulin or insulin peptides shortly after birth has been shown in animal models to successfully prevent disease $[6,7]$. Similar 'vaccination' trials in humans must await further basic and clinical research but $D R 3 / 4$ heterozygous or $D R 4 / 4$ homozygous relatives or both as shown in our study represent a very high-risk cohort for development of autoantibodies by the age of 2 years.

Preliminary data from the diabetes autoimmunity study in the young (DAISY) and Diabetes Prediction and Prevention (DIPP) study suggest, that the results obtained for offspring of parents with Type I diabetes cannot be extrapolated and extended to the general population. In DAISY, no difference was found in the distribution of islet autoantibodies at 9 and 15 months of age among infants with and without Type I diabetes susceptibility genotypes who did not have a parent with diabetes [20]. In the DIPP study, antibody frequency was increased in offspring of the general population selected for Type I diabetes-related HLA-DQB1 alleles but was considerably lower than the risk in our offspring [21]. Other genes could be relevant and their inclusion could be considered in the general population but longer follow-up and higher ascertainment of infants in these studies are needed to allow such conclusions. Therefore, with current knowledge, primary intervention trials aiming to prevent autoimmunity with invasive therapies should be limited to selected groups within children who have a family history of Type I diabetes.

Acknowledgements. This work was supported by grants from the Ministry of Research, Education and Technology, Germany (Bundesministerium für Bildung, Wissenschaft, Forschung und Technologie: BMBF 01KD89030 and 1KD9601). M. Hummel and M. Schenker are supported by this ministry. The authors are grateful to G.S. Eisenbarth (Barbara Davis Center for Childhood Diabetes, Denver, Colorado, USA) and to E. Bonifacio (San Raffaele Hospital, University of Milan, Italy) for their helpful discussion. We thank M. Dübell, J. Vordemann, U. Mollenhauer, I. Zöbisch and A. Schimmel for expert technical assistance. We also thank all obstetric departments, paediatricians and family doctors in Germany who participated in the trial for the recruitment and follow-up of fami- 
lies in BABYDIAB. In particular we acknowledge the contribution of N. Niesen (Medical Policlinic, Bonn), W. Knoll (Central Hospital Bremen-North), K. Lohe, M. Füchtenbusch, K. Brauch, W. Rabl, E. Standl (Municiple Hospital MunichSchwabing), J. Stüssel (University Woman's Clinic, Münster), and H.H. Guenter (Medical University Hannover). This work is part of the dissertation of M. Walter at the Ludwig Maximilians University, Munich, Germany.

\section{References}

1. Gorsuch AN, Spencer KM, Lister J et al. (1981) Evidence for a long pre-diabetic period in type 1 (insulin-dependent) diabetes mellitus. Lancet 335: 147-149

2. Bingley PJ (1996) Interactions of age, islet cell antibodies, insulin autoantibodies, and first-phase insulin response in predicting risk of progression to IDDM in ICA + relatives: The ICARUS data set. Islet Cell Antibody Register Users Study. Diabetes 45: 1720-1728

3. Verge CF, Gianani R, Kawasaki E et al. (1996) Prediction of type I diabetes in first-degree relatives using a combination of insulin, GAD, and ICA512bdc/IA-2 autoantibodies. Diabetes 45: 926-933

4. Schatz D, Krischer J, Horne G et al. (1994) Islet cell antibodies predict insulin-dependent diabetes in United States school age children as powerfully as in unaffected relatives. J Clin Invest 93: 2403-2407

5. The DPT-1 Study Group (1997) The Diabetes Prevention Trial-Type 1 Diabetes (DPT-1). Enrolment report. Diabetes 46: A630 (Abstract)

6. Muir A, Peck A, Clare-Salzler M et al. (1995) Insulin immunization of nonobese diabetic mice induces a protective insulitis characterized by diminished intraislet interferon- $\gamma$ transcription. J Clin Invest 95: 628-634

7. Daniel D, Wegmann DR (1996) Protection of nonobese diabetic mice from diabetes by intranasal or subcutaneous administration of insulin peptide B-(9-23). Proc Natl Acad Sci USA 93: 956-960

8. Ziegler AG, Hillebrand B, Rabl W et al. (1993) On the appearance of islet associated autoimmunity in offspring of diabetic mothers: a prospective study from birth. Diabetologia 36: 402-408

9. Roll U, Christie MR, Füchtenbusch M et al. (1996) Perinatal autoimmunity in offspring of diabetic parents: The German multicenter BABYDIAB study: Detection of humoral immune response to islet antigens in early childhood. Diabetes 45: 967-973
10. Davies JL, Kawaguchi Y, Bennett S et al. (1994) A genome-wide search for human type 1 diabetes susceptibility genes. Nature 371: 130-136

11. Hashimoto L, Habita C, Beressi JP et al. (1994) Genetic mapping of a susceptibility locus for insulin-dependent diabetes mellitus on chromosome 11 q. Nature 371: 161-164

12. Field LL, Tobias R, Magnus T (1994) A locus on chromosome 15q26 (IDDM 3) produce susceptibility to insulin-dependent diabetes mellitus. Nat Genet 189-194

13. Ronningen KS, Spurkland A, Tait BD et al. (1992) HLA class II associations in insulin-dependent diabetes mellitus among Blacks, Caucasoids, and Japanese. In: Tsuji K, Aizawa A, Sasazuki T (eds) HLA 1991, Proceedings of the 11th international histocompatibility workshop and conference, vol 1. Oxford University Press, Oxford, pp 713-722

14. Kimura A, Sasazuki T (1992) 11th International Histocompatibility Workshop reference protocol for the HLA DNAtyping technique. In: Tsuji K, Aizawa A, Sasazuki T (eds) HLA, vol 1. Oxford University Press, Oxford pp 397-419

15. Nevinny-Stickel C, Bettinotti MP, Andreas A (1991) Nonradioactive HLA class II typing using polymerase chain reaction and digoxigenin-11-2'-3'-dideoxyuridine-triphosphate labelled oligonucleotide probes. Hum Immunol 31: 7-13

16. Nevinny-Stickel C, Hinzpeter M, Andreas A, Albert ED (1991) Non-radioactive oligotyping for HLA-DR1-DR10 using polymerase chain reaction, digoxigenin-labelled oligonucleotides and chemiluminescent detection. Eur J Immunogenet 18: 323-332

17. Bodmer JG, Marsh SG, Albert ED et al. (1997) Nomenclature for factors of the HLA system 1996. Tissue Antigens 49: 293-321

18. Deschamps I, Boitard C, Hors J et al. (1992) Life table analysis of the risk of type 1 (insulin-dependent) diabetes mellitus in siblings according to islet cell antibodies and HLA markers. Diabetologia 35: 951-957

19. Eisenbarth GS, Elsey C, Liping Y, Rewers M (1998) Infantile anti-islet autoimmunity: DAISY study. Diabetes 47:A210 (Abstract)

20. Rewers M, Norris JM, Eisenbarth GS et al. (1996) Betacell autoantibodies in infants and toddlers without IDDM relatives: diabetes autoimmunity study in the young (DAISY). J Autoimmun 9: 405-410

21. Arvilommi P, Hakala R, Kupila A et al. (1998) ICA-positive children in the DIPP trial. Diabetes 47: A227 (Abstract) 